Viso - Cadernos de estética aplicada Revista eletrônica de estética

ISSN 1981-4062

No 16, jan-jun/2015

http://www.revistaviso.com.br/
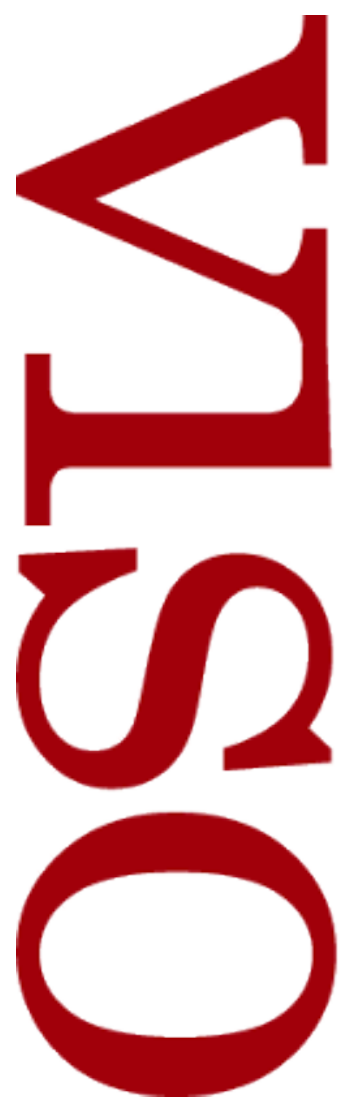

\title{
Destino e liberdade: Um ensaio sobre a teleologia latente na filosofia da arte de Arthur Danto \\ Debora Pazetto
}




\section{RESUMO}

Destino e liberdade: Um ensaio sobre a teleologia latente na filosofia da arte de Arthur Danto

Em seus escritos analíticos, Arthur Danto critica as "filosofias substantivas da história", que adotam uma atitude profética ao descrever acontecimentos passados ou presentes de acordo com um sentido histórico que pressupõe acontecimentos futuros. Contudo, em A transfiguração do lugar comum, o autor afirma claramente que busca uma definição de arte que não possa ser refutada por contraexemplos futuros. Nesse contexto, a Brillo Box de Andy Warhol aparece como a expressão da autoconsciência da arte que marca o final de sua história. No entanto, afirmar que a história da arte acabou pressupõe uma concepção substantiva da história, dirigida para um telos final que dá significado a seus estágios anteriores. Em outras palavras, contrariamente a suas pretensões analíticas anteriores, a filosofia da arte dantiana não consegue evitar previsões do futuro baseadas em uma noção teleológica da história. Em sua narrativa, tudo se passa como se a essência da arte exigisse certa história, e não como se a história construísse, em função de um imenso jogo de interesses e contingências, o conceito de arte.

Palavras-chave: teleologia - história da arte - modernismo - arte contemporânea narrativas 


\section{ABSTRACT}

Fate and Freedom: An Essay about the Veiled Teleology in the Philosophy of Art of Arthur Danto

In his analytical writings, Arthur Danto criticizes the "substantive philosophies of history", which adopt a prophetical attitude in describing past or present events according to a historical sense that presupposes future events. However, in The Transfiguration of the Commonplace, the author clearly states that he seeks for a definition of art that cannot be refuted by future counterexamples. In this context, Andy Warhol's Brillo Box appears as the expression of the self-consciousness of art that marks the end of its history. Nevertheless, to state that art history has ended presupposes a substantive conception of history, directed towards a final telos that gives meaning to its earlier stages. In other words, contrary to his previous analytical application, Danto's philosophy of art cannot prevent predictions of the future based on a teleological conception of history. In his narrative, everything happens as if the essence of art requires a certain history, and not as if history interestedly and contingently build the concept of art.

Keywords: teleology - art history - modernism - contemporary art - narratives 
PAZZETO, D. "Destino e liberdade: Um ensaio sobre a teleologia latente na filosofia da arte de Arthur Danto". In: Viso: Cadernos de estética aplicada, v. IX, n. 16 (jan-abr/2015), pp. 11-26.

DOI: $10.22409 / 1981-4062 / v 16 i / 193$

Aprovado: 08.07.2015. Publicado: 30.07.2015.

(C) 2015 Debora Pazzeto. Esse documento é distribuído nos termos da licença Creative Commons Atribuição-NãoComercial 4.0 Internacional (CC-BY-NC), que permite, exceto para fins comerciais, copiar e redistribuir o material em qualquer formato ou meio, bem como remixá-lo, transformá-lo ou criar a partir dele, desde que seja dado o devido crédito e indicada a licença sob a qual ele foi originalmente publicado.

Licença: http://creativecommons.org/licenses/by-nc/4.0/deed.pt_BR

Accepted: 08.07.2015. Published: 30.07.2015.

(C) 2015 Debora Pazzeto. This document is distributed under the terms of a Creative Commons Attribution-NonCommercial 4.0 International license (CC-BY-NC) which allows, except for commercial purposes, to copy and redistribute the material in any medium or format and to remix, transform, and build upon the material, provided the original work is properly cited and states its license.

License: http://creativecommons.org/licenses/by-nc/4.0/ 
Em sua Filosofia analítica da história, Arthur Danto critica o que ele chama de "filosofias substantivas da história", que são constituídas por projeções no futuro de estruturas que os historiadores usam para organizar os eventos do passado. Ou seja, enquanto a história tout court descreve e interpreta eventos passados, essas filosofias da história constroem discursos, que o autor considera ilegítimos, sobre toda a história, incluindo o presente e o futuro. Poderia parecer, à primeira vista, que Danto critica filosofias da história porque é logicamente impossível conhecer toda a história, uma vez que não temos acesso ao futuro. Mas a parte mais interessante de sua análise da história é a ideia de que, se não temos acesso ao futuro, também não temos acesso a todo o passado. Em outras palavras, conhecer tudo o que se passou não é apenas uma impossibilidade prática, mas igualmente lógica: "toda descrição do passado é essencialmente incompleta"1, pois nosso conhecimento do passado é limitado por nossa ignorância do futuro. Qualquer evento que descrevemos no passado pode ser redescrito posteriormente de modo diferente, dependendo de implicações que ele terá no futuro. Assim, na década de 20, algum historiador poderia escrever que Duchamp expôs um urinol como obra de arte e provocou vários escândalos, mas apenas muito tempo depois poderia escrever que esse urinol foi decisivo para toda a arte do século XX. E ainda não sabemos se futuramente teremos que acrescentar outras propriedades à Fonte, a depender de novas implicações que ela pode ter com o passar do tempo. Resumidamente, não podemos descrever completamente o passado porque ele não é algo finalizado, na medida em que continua vivo no presente e no futuro. A concepção analítica de Danto sobre a história empenha-se, portanto, na manutenção de sua abertura e incompletude.

De acordo com o pensador, as filosofias substantivas da história adotam uma atitude profética, porque descrevem acontecimentos passados ou presentes de acordo com um sentido histórico que pressupõe, no entanto, acontecimentos futuros (em relação ao momento de enunciação do filósofo ou historiador). Elas se comprometem com o que Danto denomina "realismo narrativo", que poderíamos sintetizar como uma concepção teleológica (e muitas vezes teológica) da história enquanto manifestação fenomênica e inevitável de uma narrativa que cumpre seu destino até um grand finale significativo. Conhecemos a famosa maneira como Hegel adotou essa concepção ao descrever a história do mundo como resultado dos desdobramentos do Espírito no encalço da liberdade. Sua descrição, ademais, incluía um diagnóstico sobre as regiões do planeta e as épocas que funcionariam como cenário para o percurso do Espírito em sua representação mundana. Esse diagnóstico, que colocaria em apuros qualquer autor que o enunciasse atualmente, é tendencioso e dependente de uma coleta parcial e escassa de informações histórico-sociais. Não obstante, esse aspecto acaba sendo deixado de lado, porque a relevância está no modo filosófico por meio do qual Hegel interpreta não apenas os eventos do passado, mas todo o curso da história à luz de um telos previamente dado. O significado de cada acontecimento refere-se ao momento que ocupa no percurso temporal do Espírito rumo à autoconsciência. 
Hegel redige uma prodigiosa filosofia substantiva da história, exatamente como as que Danto critica na Filosofia analítica da história. Entretanto, no fim das contas, o ex-filósofo analítico não se baseia nela para desenvolver sua tese sobre o fim da arte?

Danto acredita que descrever com verdade e precisão fatos do passado é condição necessária para fazer história: "devo dizer que o mínimo que historiadores fazem é tentar produzir enunciados verdadeiros, ou proporcionar descrições verdadeiras, de eventos no seu passado". ${ }^{2}$ No entanto, ele reconhece que historiadores não apenas acumulam e registram fatos, mas constroem descrições que se transformam em narrativas, explicações e teorias. Ou seja, suas descrições não são opacas e vazias, pois criam significados sobre os eventos que descrevem: eventos históricos são eventos-sob-umadescrição, são eventos-interpretados-por-uma-narrativa. Embora a interpretação e a narrativa façam parte da história, ela precisa remeter-se constantemente a eventos reais e descrevê-los com verdade, para distinguir-se da ficção. Assim, meras descrições de fatos reais sem interpretação são um acúmulo vazio de registros, um ofício de cartório, enquanto narrativas sem o atestado do real são ficções.

A consequência disso é que, como novos fatos sempre ocorrem, historiadores posteriores podem continuamente criar novas interpretações baseadas em outros fatos que aconteceram depois, aos quais os historiadores anteriores não tinham acesso. Ou seja, enquanto filósofo analítico da história, Danto defende que um evento que foi descrito e assimilado através de uma interpretação histórica pode passar a ser conhecido por outra interpretação em um momento posterior. Ora, como nunca conhecemos todo o passado, uma vez que somos limitados pela ignorância das implicações que ele terá no futuro, deveríamos ser coagidos a assumir que narrativas são sucessivamente incompletas e que a história é sempre aberta. Efetivamente, de acordo com o belo e democrata prefácio de Lydia Goehr, "o que está sempre em causa para Danto é a presença da abertura. Manter o futuro aberto é não fazer afirmações substanciais sobre ele, manter o futuro aberto é manter o presente aberto, assim como o passado" ${ }^{3}$

Contudo, alguns anos depois, Danto não afirma claramente que busca uma definição de arte que não possa ser refutada por contraexemplos futuros? No prefácio de $A$ transfiguração do lugar comum, ele argumenta:

Meu ponto de vista é que o inevitável vazio das definições de arte tradicionais provém do fato de que todas elas se basearam em aspectos que as caixas de Warhol tornaram irrelevantes para definições dessa natureza; quer dizer, as revoluções no mundo da arte deixaram as definições bem-intencionadas sem quaisquer recursos em face do arrojo das novas obras de arte. Qualquer definição que pretenda sustentar-se precisa adquirir imunidades contra essas revoluções; eu gostaria de crer que depois das caixas Brillo as possibilidades para isso realmente se encerram e a história da arte chegou, de certa maneira, a um fim. ${ }^{4}$ 
Ou seja, a obra de Warhol imunizou a filosofia contra possíveis surpresas fenomênicas que refutariam suas definições teóricas ao ostentar, como tantas vezes ocorreu, algo que é obra de arte mesmo ultrapassando as fronteiras das definições de arte arduamente elaboradas pelos filósofos. Então a história não pode mais apresentar surpresas? Interditou-se a possibilidade de surgirem novos eventos que legitimariam redescrições por parte de futuros historiadores? Em 1964, o artista americano Andy Warhol expôs a Brillo Box - essa é a opaca e vazia descrição do fato, tal como poderíamos encontrar nos registros da Stable Gallery e não em um livro de história da arte. Para tornar-se uma descrição histórica, o fato precisa ser interpretado e contextualizado por uma narrativa. Mas essa narrativa, de acordo com as restrições que Danto impõe à história em sua filosofia analítica, deveria basear-se em fatos reais do passado. Assim, nosso autor poderia descrever historicamente a Brillo Box de acordo com as informações reais de que dispunha até 1984 (ano em que a descreve como marco do fim da arte em O fim da arte), isto é, como uma obra de arte que provocou diversas reações, que teve certo papel fundamental na pop art, que inspirou artistas e filósofos, etc. Mas ele pode legitimamente descrevê-la enquanto o fim da história da arte ou enquanto fim da possibilidade de "revoluções" em arte? Ora, essa interpretação pressupõe um telos, uma concepção da história como um todo, um conhecimento do futuro. E a perspectiva desde a qual se poderia contemplar o futuro como algo determinado é exatamente o que Danto chama de profecia ou de filosofia substantiva da história: "o profeta é aquele que fala sobre o futuro de uma maneira que é apropriada somente para o passado, ou que fala do presente à luz de um futuro que se trata como um fait accompli”. ${ }^{5}$ Então, após suas censuras analíticas, o autor acabou por converter-se a uma perspectiva teleológica da história?

Danto certamente percebe a descontinuidade entre seus ataques analíticos às filosofias substantivas da história e sua filosofia da história da arte. Como um bom vidente, ele antecipa esse tipo de reprimenda e justifica-se, explicando que sua tarefa é diferente ele alega fazer uma "profecia do presente":

A diferença entre a profecia marxista e a minha é a condição de uma vida humana não alienada, que Marx apenas delineou para um futuro histórico distante. A minha é o que se pode chamar de profecia do presente. Ela vê o presente, por assim dizer, como revelado. Só o que posso dizer sobre o futuro é que este é o estado final, a conclusão de um processo histórico cuja estrutura se torna visível de uma só vez. Isso é, na verdade, muito próximo de lançar um olhar para o fim da história para ver como ela resultou, com a seguinte diferença: nós não pulamos etapa alguma, mas vivemos através das sequências históricas que nos conduziram até aqui: este é o fim da história da arte. ${ }^{6}$

Dessa maneira, Danto se restringe a narrar o passado recente como o desgaste de uma narrativa histórica que finalmente acabou e o presente como ausência de narrativas mestras. Entretanto, afirmar que a história da arte acabou porque atingiu sua autoconsciência pressupõe mais do que isso: não apenas uma concepção da história da arte como um todo, dirigida para um telos final que dá significado a seus estágios anteriores - a árdua ascensão epocal da arte rumo a si mesma, até sua redentora 
cognição final -, mas também uma previsão sobre o futuro, a saber, que não haverá mais narrativas mestras nem revoluções que ponham em xeque a autoconsciência finalmente adquirida. Afirmar que este é o estado final não deixa de ser uma profecia do futuro. Pode não ser uma profecia tradicional como as que estabelecem o que acontecerá futuramente, mas é uma profecia sobre o que não acontecerá. Danto prevê que no futuro não haverá mais surpresas que a arte possa apresentar à sua definição filosófica. Pois ela atingiu seu telos, o tão esperado final para o qual toda a história da arte supostamente se direcionava. Sem dúvida, temos aí um exemplo do que o próprio Danto criticava anteriormente como "filosofia substantiva da história".

Não é por coincidência que o pensador recorre constantemente a Hegel quando aborda o tema do fim da história da arte, que não é evidentemente o fim da arte, mas a interpretação dantiana de que o conceito de arte viveu todos os seus momentos de inconsciência (tese), em seguida, viveu a consciência de si como um problema (antítese), até que adquiriu as condições apropriadas para compreender sua própria identidade (síntese). Essas condições são proporcionas pelas vanguardas americanas da década de sessenta e a compreensão da identidade da arte é proporcionada por Danto, narrador do Bildungsroman cujo telos é a definição de arte, imunizada contra futuras revoluções por parte do "arrojo das novas obras de arte".

Como Danto pode ter certeza de que a Brillo Box marca o fim e não uma etapa dentro da história da arte, ou mesmo o início de uma narrativa mestra que ainda se encontra em vias de ser elaborada? Como ele pode garantir que sua interpretação da obra de Warhol é a única possível e que não será revista futuramente no contexto de outra narrativa ou à luz de novos fatos? O autor pressupõe uma estrutura linear da história da arte, que progrediu de certo modo até atingir o limite de seu conceito. Mas poderíamos imaginar uma estrutura circular, na qual os artistas decidem retomar as narrativas iniciais e, com o passar das gerações, voltam espontaneamente às ingênuas representações miméticas que acreditam ser a essência da arte. Também poderíamos imaginar uma estrutura fragmentada, com crescente grau de sofisticação, na qual a narrativa mimética é um conto dentro da narrativa modernista, que é um conto dentro da narrativa da arte contemporânea, que é um conto dentro de uma narrativa mais ampla que ainda não conseguimos enxergar porque só podemos ver de dentro do conto em que nos encontramos. Essa sinédoque poderia se estender ad infinitum e teríamos que nos satisfazer com o grau de conhecimento limitado do nosso próprio conto, que engloba os contos passados, mas é englobado por misteriosos e insondáveis contos futuros. E quiçá manter o olhar fixo em nosso próprio tempo seria o modo mais autêntico de ser contemporâneo. Talvez para perceber suas sombras e não apenas suas luzes, como dizia Agamben sem perder a dimensão de que ser contemporâneo é também saber que se pertence e que se é limitado por sua própria época, irrevogavelmente.

Portanto, como Danto pode declarar o fim das narrativas sem se autoproclamar o privilegiado profeta da arte, que recebeu uma centelha do olhar divino e pôde ver toda 
sua história? Contra a interpretação de Lydia Goehr, o mais importante para Danto, ao menos em sua filosofia da arte, não é manter o futuro aberto: é definir a arte, sendo essa definição dependente de sua história filosófica - e substantiva - da arte, uma vez que se identifica com a autoconsciência adquirida em seu fim. Por conseguinte, não é possível separar sua definição de arte de $A$ transfiguração do lugar comum de sua tese sobre o fim da história da arte. Por esse motivo o autor se autodenomina "essencialista histórico": sua definição diz respeito à essência da arte, portanto deve valer para todos os lugares e épocas, mas essa essência só pode ser revelada historicamente e, não por acaso, no mundo da arte norte-americano da década de sessenta. Assim, o mundo da arte funciona como condição necessária em sua definição e é formado por meio dos moldes narrativos "em que se organizam as obras de arte com o passar do tempo, e que compartilham as motivações e atitudes de artistas e do público que internalizou essas formas" ${ }^{7}$

A tese dantiana sobre o fim da arte ampara-se em ideais libertadores, isto é, pretende liberar a arte do peso da história, das teorias filosóficas, das ideologias e das definições que the impõem uma essência alheia a sua natureza:

Sinto que minha tese era liberacionista - agora que o fim da arte aconteceu, os artistas estão livres do fardo da história da arte. Eles não estão mais restritos pelo imperativo de conduzir adiante a narrativa. Nada na arte poderia mais ser invalidado através da crítica de que era historicamente incorreto. Toda e qualquer coisa era agora disponível para os artistas. $^{8}$

São boas intenções, embora amparadas por certo exagero em relação ao poder da crítica e da teoria da arte de restringir ou invalidar a atividade criativa. É verdade que a narrativa mimética foi tão intimamente ligada à ideia das artes visuais que pouco se fez no Ocidente, até a modernidade, que escapasse a esse modelo. Todavia, a partir das primeiras vanguardas, os artistas adquiriram certa autonomia - até mesmo teórica, tornando-se críticos e defensores de seu próprio modus operandi artístico - e mantiveram-se simultaneamente livres e restritos a várias formas de narrativa e de avaliação de suas obras. Embora houvesse imperativos históricos que procuravam determinar como fazer arte, os artistas sempre foram capazes de desafiá-los; e frequentemente encontraram o sentido de seu estilo nesse ato de transgressão. Mais do que isso, em geral as obras mais significativas da modernidade surgiram exatamente em tais momentos de ruptura. O otimismo dantiano em relação à liberdade da arte contemporânea funda-se na constatação de que não há mais o "fardo" das grandes narrativas. Além de acentuar excessivamente a alçada desse fardo, Danto parece atenuar o poder restritivo da crítica de arte que continua existindo "pós-historicamente". Assim como no modernismo, a crítica - sem mencionar a curadoria e o mercado - barra uma pulsão criativa espontânea, conquanto os artistas costumam levar em consideração o que se espera deles e o modo como suas obras serão avaliadas. Mas, ainda assim, eles continuam livres para romper com qualquer expectativa. Em suma, tanto no modernismo quanto na arte contemporânea há um jogo produtivo entre liberdade criativa 
e restrição teórica (por vezes, entre liberdade teórica e restrição criativa).

De todo modo, Danto propõe uma definição libertadora, isto é, consistente com a ideia de que tudo pode ser arte. Entretanto, estabelecer essa "regra de não ter mais regra" ou essa "história de não ter mais história" não é ainda um modo filosófico de determinar a arte? O autor não determina que o objetivo final da arte é a autoconsciência, resumida na ideia de que qualquer coisa pode ser arte se for assim interpretada no mundo da arte?

De certo modo, ao afirmar que a história da arte acabou, Danto determina o "momento Brillo Box" com uma interpretação que passa a ser a única possível. Pois se a história acabou, os futuros "historiadores" não podem propor novas descrições à luz de novos eventos. Acima de tudo, como o autor pode postular que não surgirão outras narrativas? Danto procura resolver esse problema com a "questão do estilo", sendo que "estilo", nesse contexto, tem um significado bem diferente do desenvolvido em $A$ transfiguração do lugar comum. Seu argumento consiste basicamente em considerar o estilo como um conjunto de propriedades utilizadas para definir filosoficamente o que deve ser uma obra de arte. De acordo com essa concepção, a mimese era um estilo, depois as vanguardas geraram diversos estilos, até que a Era dos Manifestos terminou "quando a filosofia se separou do estilo em virtude do aparecimento, em sua verdadeira forma, da questão 'o que é a arte?"'. ${ }^{9}$ Supostamente, a verdadeira forma dessa questão foi desvendada pela interpretação de Danto a respeito da Brillo Box. Todavia, esta é uma forma de encobrir o problema mais do que enfrentá-lo. Afinal, o evento histórico canonizado pela obra de Warhol não poderia ser interpretado de outro modo? A própria questão dos indiscerníveis, tal como foi enunciada por Danto, poderia levar a uma nova narrativa que defendesse, por exemplo, que agora que sabemos que qualquer coisa pode ser arte, essa liberdade não deve ser usada para inserir qualquer obra nas instituições legitimadoras simplesmente para ampliar o fetichista e elitizado consumo cultural ou para movimentar esse setor do mercado. Os futuros artistas e teóricos poderiam postular que a arte deve ter objetivos mais engajados, como criar sentidos para os povos, restaurar sentimentos importantes entre os homens, fazer política, e assim por diante. Aos poucos, esse discurso poderia transformar-se em uma narrativa mestra que redefiniria a arte identificando-a com esse estilo, e certos trabalhos que hoje são facilmente implantados em museus, como as pinturas de Romero Britto, poderiam deixar de ser considerados obras de arte.

Ou seja, a tese de Danto sobre o fim da arte não é apenas uma "profecia do presente" e não escapa à estrutura teleológica que ele censurava alguns anos antes, pois determina o telos da história da arte como certo tipo de autoconsciência e como ausência de narrativas. Ao menos o telos escolhido é libertário e deixa a arte pós-histórica seguir alegremente seus instintos sem importar-se com a necessidade de revoluções e ideologias. Dito de outro modo, o filósofo compreende a história da arte como um destino inevitável cujo sentido final era a liberdade da arte em relação à própria história. Nesse 
contexto, o aspecto mais problemático do pensamento dantiano é o modo como ele legitima uma interpretação arbitrária do passado com base em sua história filosóficoteleológica da arte. A discussão sobre o fim da arte só faz sentido em referência às narrativas que o pensador seleciona como mestras. E assim como Hegel e os "profetas" em geral, ele seleciona de maneira parcial os momentos históricos relevantes de acordo com seus interesses teóricos.

A seleção de duas grandes narrativas mestras é provavelmente o ponto mais passível de crítica na teoria dantiana sobre o fim da arte. Pois as narrativas que escolhe fundamentadas nas concepções de Giorgio Vasari e Clement Greenberg - são regionalistas e excludentes em relação a vários tipos de arte realizados na época em que esses discursos vigoravam. E mesmo que Danto explique que essas narrativas falharam em contato com a arte moderna e contemporânea, respectivamente, o simples fato de escolhê-las como eixo central da história da arte legitima uma perspectiva na qual esta é assumida como ideologia do progresso e história dos vencedores, para usarmos palavras de Walter Benjamin. Vasari já era criticado em sua época por atribuir os grandes desenvolvimentos do Renascimento apenas à arte florentina. De modo semelhante, o programa crítico de Greenberg é completamente americanista. Sua apologia do expressionismo abstrato como a arte genuinamente americana e a arte moderna por excelência, isto é, a mais capacitada para rastrear as formas puras da pintura de modo direto e sustentável, coloca sob grandes holofotes apenas um pequeno grupo de pintores nova-iorquinos e supõe que toda a arte feita no resto do mundo dormita debilmente nas sombras. Esse mesmo grupo de pintores assume um projeto nacionalista: "esse país ainda não tinha feito nenhuma contribuição para a corrente dominante de pintura ou escultura. O que uniu os 'expressionistas abstratos', mais do que qualquer outra coisa, foi sua resolução para romper com essa situação". ${ }^{10}$ Claramente, vemos aí uma estratégia cultural relacionada com a perda do monopólio artístico internacional de Paris nas décadas de trinta e quarenta, e com a transferência parcial desse núcleo para Nova lorque. Na dianteira desse projeto, a estética de Greenberg revela-se como um panegírico à arte norte-americana e, portanto, é tão ideológica e restritiva quanto os manifestos vanguardistas. Ora, nada contra a arte regionalmente engajada, mas propor a "american-type painting" como sinônimo de arte modernista é cometer a clássica falácia da amostra insuficiente, isto é, uma generalização apressada a partir de dados insuficientes para sustentá-la. Havia, afinal, muitos outros "types" de arte sendo feitos e reivindicados como modernismo pelo mundo e até mesmo nos Estados Unidos. ${ }^{11}$

Ao escolher a estética de Greenberg como a grande narrativa do modernismo, Danto legitima a mesma falácia cometida por ele. Embora não "concorde" com a estética greenbergiana e seja consciente de que ela fracassa ao confrontar-se com a arte contemporânea, Danto Ihe atribui uma importância excessiva e tendenciosa. Por que, afinal, o autor não selecionou outros críticos e teóricos da arte moderna, como Roger Fry, Kanhweiler e Panofsky? Por que não Alfred H. Barr ou Mário Pedrosa? Mesmo que insistisse em permanecer exclusivamente no contexto da crítica de arte americana, 
poderia certamente ter escolhido Harold Rosenberg como o grande narrador do modernismo. Rosenberg é considerado um dos críticos mais incisivos e influentes do mesmo expressionismo abstrato defendido por Greenberg. Era no mínimo tão famoso quanto seu rival formalista, com a diferença de que analisava as mesmas obras de arte de uma perspectiva existencialista. As obras eram as mesmas, mas a interpretação crítica fundava-se no conteúdo temático-expressivo e não na bidimensionalidade, assim como o valor da obra fundava-se no ato criativo e não na pureza dos meios de representação. ${ }^{12}$ Danto o negligencia provavelmente porque seria difícil construir uma narrativa desenvolvimentista e progressiva baseada no ato criativo, na expressão e no encontro dramático e pessoal de cada pintor com a tela. Ou seja, é a sua narrativa teleológica - o conceito de arte, em sua história fenomênica, passa por duas grandes etapas nas quais se desenvolve e progride até chegar à autoconsciência/definição filosófica/fim das narrativas/pós-história - que demanda a escolha arbitrária de Clement Greenberg como o porta-voz do espírito do tempo moderno na arte. Mesmo que esse "porta-voz" da modernidade exclua ou negligencie grande parte da arte moderna, e não apenas várias das primeiras vanguardas, mas movimentos concomitantes ao expressionismo abstrato americano, como o surrealismo, que continuava vigoroso na França e em Portugal, o movimento construtivo no Brasil ${ }^{13}$ e o realismo socialista na União Soviética. Para Danto, importa apenas que, entre todos os teóricos e críticos da arte que ele poderia ter escolhido, Greenberg foi o que mais fundamentou uma concepção de progresso da arte como inevitabilidade histórica.

Se a narrativa das narrativas de Danto já é tendenciosa e regionalista, o é tanto mais sua apoteose da Brillo Box, exposta em 1964, como a primeira grande manifestação da autoconsciência da arte. $\mathrm{O}$ autor tem razão em notar que o formalismo de Greenberg e sua tese purista em relação aos meios de expressão de cada arte não correspondem à realidade artística dos anos sessenta (nem à realidade social). O problema, além da evidente superestimação do papel teórico de Greenberg, é o modo como ele identifica essa ruptura com a Brillo Box e com o programa típico da pop art de iconizar objetos banais da cultura popular como obras de arte. A argumentação de Danto é americanocêntrica e exagera a importância da pop art em relação ao início da arte contemporânea. Sua identificação da Brillo Box como momento crucial apoia-se em um ponto de vista geograficamente e culturalmente limitado, que ignora outros tipos de ruptura com a arte moderna que estavam sendo realizados de modo igualmente radical, até mesmo antes do apogeu da pop art nas galerias americanas. Nessa perspectiva, Marc Jimenez escreve uma crítica virulenta que merece ser citada na íntegra:

Entrementes, até simultaneamente, aparecem diferentes movimentos e tendências que contestam a noção de obra de arte tradicional de modo mais decisivo do que fez a pop art. Esse é o caso, principalmente, do happening, criado em 1959 por Allan Kaprow. É também o caso do Novo Realismo, fundado por Pierre Restany em 1960, que parte em busca de "novas abordagens perspectivas do real", ou do Fluxus, lançado por George Maciunas em 1960, ou ainda da arte conceitual impulsionada por Joseph Kosuth em 1964. A noção de concept art proposta por Henry Flint, data, ela também, de 1961. 
Todos assumem amplamente a herança de Marcel Duchamp, de modo inegavelmente mais radical do que a pop art sobre o plano do engajamento social e político. Danto não Ihes confere nenhuma palavra, preferindo fundar sua estética sobre a arte que porta ao mais alto grau os valores da América, uma arte que os marchands, as mídias e as galerias, em outras palavras, a instituição - no sentido anglo-saxão - promoveram ativamente. $^{14}$

Com efeito, o privilégio que Danto outorga à Brillo Box e à pop art não é bem fundamentado. Se a questão era apenas a apresentação de um objeto indiscernível dos objetos banais, a Fountaine, de 1917, e En prévision d'un bras cassé, de 1915, já o tinham feito meio século antes. Danto não elabora um raciocínio convincente e sustentável para explicar por que ele escolhe Warhol, em vez de Duchamp, como instaurador do seu conhecido problema dos indiscerníveis na arte. Em uma entrevista relativamente recente, o autor simplesmente postula que "Duchamp escolheu uma via contrária ao acesso à arte que privilegiava o olho, forjando uma arte absolutamente intelectual. Warhol, por sua vez, era na minha opinião um artista mais rico, pois ele tinha uma filosofia do mundo". ${ }^{15} \mathrm{O}$ filósofo já havia ensaiado uma opinião semelhante em Após o fim da arte, no qual explica que a diferença entre Warhol e Duchamp pode ser compreendida pelo contexto cultural mais amplo: o artista francês, ao apresentar objetos comuns como obras de arte, podia estar "depreciando a estética" e "testando os limites da arte", mas a mesma atitude, por parte da celebridade americana da pop, celebrava "as coisas mais comuns dos modos de vida mais comuns" ou "os objetos e os ícones da experiência cultural comum, o equipamento comum da mente do grupo no momento presente da história". ${ }^{16}$ Assim, a pop art significaria o fim da história da arte porque "se voltou contra a arte como um todo em favor da vida real" ${ }^{17}$, e respondeu a um sentimento universal da época, de que as pessoas queriam desfrutar suas vidas e "buscar a felicidade" no momento presente, e não em um idealizado e distante tempo vindouro. Isso significa que a apologia da pop como início da arte contemporânea não se funda na exposição dos objetos banais dentro das galerias, mas na celebração da vida real e da experiência cultural comum? É claro que se a questão fosse apenas a apresentação do objeto banal transfigurado em arte, Danto precisaria ter identificado o momento de ruptura nos ready-mades de Duchamp.

Mas se a questão é a celebração da vida real e da cultura comum, precisamos notar que isso estava sendo feito no início da década de sessenta por todos os movimentos mencionados acima por Marc Jimenez e por muitos outros artistas. Com a diferença de que, em vez de fetichizar as etiquetas da indústria cultural e glorificar os objetos do consumo de massa como a pop art, esses artistas apropriavam-se da realidade cotidiana de modo mais relutante. Assim, Arman expõe suas primeiras Poubelles repletas de dejetos burgueses em 1959; John Cage compõe 4'33" em 1952, propondo os sons fortuitos do ambiente e do público como música; Christo começa a expor seus primeiros objetos cotidianos (garrafas, roupas, máquina de calcular) embrulhados em 1958; em 1963, Spoerri expõe 723 utensílios de cozinha montados sobre uma prancha e prepara refeições na Galeria J, em Paris, enquanto críticos de arte, ironicamente de acordo com 
sua função de explicar o trabalho dos artistas ao público, assumem o papel de garçons; em 1955, Yoko Ono apresenta uma performance que consiste em mostrar ao público um palito de fósforo sendo completamente queimado, e nos anos seguintes continua criando diversas performances e instruções com o objetivo de transfigurar a banalidade de objetos e ações corriqueiros. Em Paris, no início da década de sessenta, forma-se o GRAV (Group de Recherches d'Art Visuel), que critica a clausura da arte nas galerias e nos museus, bem como seu afastamento do grande público - o que levou seus participantes a tomar as ruas para interpelar os passantes, oferecendo-lhes objetos manipuláveis e participativos que poderiam interessá-los mais do que a arte institucionalizada. No Brasil, Hélio Oiticica começa a criar os Parangolés em 1960, a partir do contato direto com a cultura popular das favelas do Rio de Janeiro e com a escola de samba Estação Primeira de Mangueira. O artista é plenamente consciente do sentido coletivo e popular de sua obra, afirmando que ela "visa abarcar a grande massa popular e dar-Ihe também uma oportunidade criativa", e que "há a exaltação dos valores coletivos nas suas aspirações criativas mais fundamentais ao mesmo tempo em que é dada ao indivíduo a possibilidade de inventar, de criar - é a retomada dos mitos da cor, da dança, das estruturas criativas enfim". ${ }^{18}$

Em suma, Duchamp apresentou objetos indiscerníveis dos objetos banais cinquenta anos antes de Warhol. E alguns anos antes da Brillo Box, todos os artistas mencionados acima transformaram em arte "as coisas mais comuns dos modos de vida mais comuns". E fizeram isso usando a cultura popular genuína, nascida e criada pelo povo, e não a cultura popular imposta, vendida e fetichizada pela indústria cultural. Ou seja, Danto não tem nenhum motivo plausível, a não ser sua pequena perspectiva americanocêntrica e sua vontade de corroborar sua própria narrativa das narrativas, para explicar desse modo o telos final da história da arte: "endosso a narrativa da história da arte moderna em que a pop desempenha o papel filosoficamente principal. Em minha narrativa a pop marcou o fim da grande narrativa da arte ocidental ao trazer à autoconsciência a verdade filosófica da arte". ${ }^{19}$

Danto teria sido mais coerente se não tivesse identificado de modo tão restrito, excludente e regional os três grandes momentos da história da arte. Ele poderia, por exemplo, ter descrito a narrativa da arte moderna a partir das transformações em geral do início do modernismo e as inúmeras reivindicações das vanguardas, em vez de usar a estética de Greenberg. E poderia ter descrito o ambiente pluralista, múltiplo e independente de narrativas que se forma entre o final da década de cinquenta e a década de oitenta, em quase todo o mundo ocidentalizado, como a configuração da arte contemporânea e a conquista gradual da consciência coletiva de que tudo pode ser arte, em vez de responsabilizar unilateralmente a Brillo Box e a pop art. Danto interpreta a história da arte como um destino que se desenvolve progressivamente em direção à autoconsciência, à liberdade pós-histórica, que aparece como o telos: final e finalidade desse destino. Em outras palavras, contrariamente a suas pretensões analíticas anteriores, a filosofia da arte dantiana não consegue evitar previsões do futuro baseadas 
em uma noção teleológica da história. Em sua narrativa, tudo se passa como se a essência da arte exigisse certa história, e não como se a história construísse, em função de um imenso jogo de interesses e contingências, o conceito de arte.

\section{bibliografia complementar}

CHATEAU, D. La Question de la question de l'art: note sur l'esthétique analytique (Danto, Goodman et quelques autres). Saint-Denis: Presses universitaires de Vincennes, 1994.

DANTO, A. O descredenciamento filosófico da arte. Trad. Rodrigo Duarte. Belo Horizonte: Autêntica Editora, 2014.

$21,2003$. The Abuse of Beauty: aesthetics and the concept of art. The Paul Carus Lectures What art is. Yale: Yale University Press, 2013.

\section{* Debora Pazetto é professora do CEFET/MG.}

1 DANTO, A. Narration and knowledge. Tradução própria para fins acadêmicos. New York: Columbia University Press, 2007, p. 17.

${ }^{2}$ Ibidem, p. 25.

${ }^{3}$ Ibidem, p. xli.

${ }^{4}$ DANTO, A. A transfiguração do lugar comum. Tradução de Vera Pereira. São Paulo: Cosac Naify, 2010, p. 26.

${ }^{5}$ DANTO, A. Narration and knowledge. Op. cit.,p. 57.

${ }^{6}$ DANTO, A. Após o fim da arte: a arte contemporânea e os limites da história. Tradução de Saulo Krieger. São Paulo: Odysseus Editora, 2006, pp. 50-51.

${ }^{7}$ Ibidem, p. 53.

${ }^{8}$ DANTO, A. "Crítica de arte após o fim da arte". Tradução de Cláudio Miklos In: DANTO, A. Unnatural Wonders. Essays from the Gap between Art and Life. New York: Farrar, Straus, Giroux, 2005, pp. 3-18, p. 3.

${ }^{9}$ DANTO, A. Após o fim da arteOp. cit., p. 51.

10 "This country had not yet made a single contribution to the mainstream of painting or sculpture. What united the 'abstract expressionists' more than anything else was their resolve to break out of this situation". GREENBERG, C. Art and Culture: Critical Essays. Boston: Beacon Press, 1961, p. 228.

${ }^{11}$ O próprio Danto menciona o exemplo de Hoper, que fazia pinturas realistas em pleno auge do expressionismo abstrato nos Estados Unidos. DANTO, A. Após o fim da arte. Op. cit., p. 131. Alfred Barr, que foi um importante historiador de arte americano, além de diretor do Museu de Arte Moderna de Nova lorque, de 1929 a 1943, considerava Hopper o pintor mais interessante da América e fez uma retrospectiva de seu trabalho no MoMa em 1933. O curioso é que mesmo em vista desses fatos, Danto legitima a estética de Greenberg como o paradigma da teoria modernista, que por sua vez legitima o expressionismo abstrato como o paradigma da arte moderna. 
${ }^{12}$ ROSENBERG, H. The American Action Painters. Publicado originalmente em Art News, v. 51, n. 8(Dec. 1952).

${ }^{13}$ O Grupo Frente, liderado por Ivan Serpa, é o apogeu do movimento construtivo no Brasil. Diversos participantes do grupo, entre eles o próprio Serpa, fazem pinturas abstratas e geométricas, que poderiam ser admitidas como modernas pela crítica greenbergiana. No entanto, artistas como Elisa Martins, que fazia pinturas primitivas, ou Abraham Palatnik, que fazia objetos cinéticos, também foram admitidos no grupo sem problemas. É extremamente instrutivo ler a crítica que Mário Pedrosa oferece no texto de apresentação da segunda mostra do Grupo Frente, em 1955: "os seus membros são todos jovens. [...] Isso quer dizer que o grupo está aberto... para o futuro, para as gerações em formação. Mais promissor ainda é o fato de o grupo não ser uma panelinha fechada, nem muito menos uma academia onde se ensinam e se aprendem regrinhas e receitas para fazer Abstracionismo, Concretismo, Expressionismo, Futurismo, Cubismo, realismos e neo-realismos e outros ismos. [...] Aí está Elisa ao lado de Serpa; Val junto a Lygia Clark; aí estão Franz Weissmann e Lygia Pape; Vincent, romântico, encostado a João José, concretista; e Décio Vieira e Aluísio Carvão, irmãos mas tão diferentes! E não falemos nesse terrível Abraham Palatnik, inventor, construtor, novelista". PEDROSA, M. Disponível em: <http://www.macvirtual.usp.br/mac/templates/projetos/seculoxx/modulo3/frente/index.html>. Acesso em 14.04.2014. Esse belo exemplar de crítica que elogia a mistura de estilos foi escrito no mesmo ano em que Greenberg escrevia American-Type Painting em defesa do expressionismo abstrato, o "ismo" por excelência guiado pelas regras do purismo na pintura, e afirmava que nada de tão importante havia acontecido desde o cubismo na história evolutiva da pintura. A crítica de Pedrosa defende uma arte aberta, pluralista e libertária, e foi escrita nove anos antes do surgimento da Brillo Box, que supostamente finaliza as narrativas e liberta a arte para seguir qualquer estilo (ideia que só foi desenvolvida por Danto quase trinta anos depois.

14 JIMENEZ, M. Tradução própria para fins acadêmicos. La querelle de l'art contemporain. Paris: Gallimard, 2005, pp. 212- 213.

15 DANTO, A. "L'art à la limite: Rencontre avec Arthur Danto". Tradução própria para fins acadêmicos. Recherches en estéthique. Revue du C.E.R.E.A.P., n. 10 (Octobre, 2004), p. 16.

${ }^{16}$ DANTO, A. Após o fim da arte. Op. cit., p. 144.

${ }^{17}$ Ibidem, p. 145.

${ }^{18}$ OITICICA, H. "Parangolé: uma nova fundação objetiva na arte". In : Ciclo de exposições sobre arte no Rio de Janeiro - 5. OPINIÃO 65. Curadoria Frederico Morais; apresentação Frederico Morais. Rio de Janeiro: Galeria de Arte Banerj, 1985.

${ }^{19}$ DANTO, A. Após o fim da arte. Op. cit., p. 135. 